\title{
Word Length and Orthographic Neighborhood Size Effects in the Left and Right Cerebral Hemispheres
}

\author{
Michal Lavidor and Andrew W. Ellis \\ University of York, York, England, United Kingdom
}

\begin{abstract}
Previous studies have reported an interaction between visual field (VF) and word length such that word recognition is affected more by length in the left VF (LVF) than in the right $\mathrm{VF}(\mathrm{RVF})$. A reanalysis showed that the previously reported effects of length were confounded with orthographic neighborhood size $(\mathrm{N})$. In three experiments we manipulated length and $\mathrm{N}$ in lateralized lexical decision tasks. Results showed that length and VF interacted even with $\mathrm{N}$ controlled (Experiment 1); that $\mathrm{N}$ affected responses to words in the LVF but not the RVF (Experiment 2); and that when length and $\mathrm{N}$ were combined, length only affected performance in the LVF for words with few neighbors. ๑ 2002 Elsevier Science (USA)
\end{abstract}

Key Words: orthographic neighborhood size; word length; hemispheric differences; lateralization; visual lexical decision.

\section{INTRODUCTION}

Several studies in the past have reported an interaction between visual hemifield (VHF) and word length such that the number of letters in a word has a stronger effect in the left visual field (LVF) than in the right visual field (RVF) (e.g., Bouma, 1973; Gill \& McKeever, 1974). However, these studies did not control some of the other properties of the stimulus materials that are known to be correlated with word length, such as the imageability of stimulus words (Young, Bion, \& Ellis, 1980). Further studies that did control imageability and frequency of the stimulus words reported the same interaction for lexical decision reaction time (RT) (Bub \& Lewine, 1988; Chiarello, 1988; Ellis, Young, \& Anderson, 1988; Iacoboni \& Zaidel, 1996), word identification accuracy (Young \& Ellis, 1985), and semantic decision RT (Ellis et al., 1988). But the reduced effect of length in the RVF only occurred when words were presented in a standard, horizontal format. Distorting the format-for example, by rotating the letters (Babkoff, Faust, \& Lavidor, 1997) or presenting vertical words (Bub \& Lewine, 1988; Ellis et al., 1988)—caused word length effects to occur in both hemifields. Nonword report also shows length effects in both hemifields (Bub \& Lewine, 1988; Ellis et al., 1988).

This study was supported by the European Commission, Marie Curie fellowship grant, Contract No. HPMF-CT-1999-00205.

Address correspondence and reprint requests to Michal Lavidor, Department of Psychology, University of York, York YO10 5DD, England. Fax: +44(0)1904 433181. E-mail: M.Lavidor@ psych.york.ac.uk. 
Based on this pattern of results, the concept of two "modes" of visual word recognition was developed. One mode operates independent of string length and is seen only in the left hemisphere (LH/RVF) analysis of familiar words in familiar formats, while a second mode is length dependent, is the only mode possessed by the right hemisphere (RH/LVF), and is employed by the LH when processing nonwords and familiar words in unusual formats (Bub \& Lewine, 1988; Ellis et al., 1988; Eviatar \& Zaidel, 1991; Iacoboni \& Zaidel, 1996; Young \& Ellis, 1985).

The present article is concerned with the influence on word recognition of word length, and of another word property that correlates with length, and that has not been controlled in previous studies of the length $\times$ visual hemifields interaction, namely the number of orthographic neighbors that a word has. Orthographic neighborhood size (" $\mathrm{N}$ ") is defined as the number of words differing from a target word by one letter (i.e., "neighbors") (Coltheart, Davelaar, Jonasson, \& Besner, 1977). Previous studies have shown, in general, facilitation effects in lexical decision for words with larger N's ("friendly"' words) (Laxon, Coltheart, \& Keating, 1988; Laxon, Masterson, \& Moran, 1994). N effects are robust when frequency, regularity, and age of acquisition are controlled, though frequency of the neighboring words may interact with N (Perea \& Pollatsek, 1998; Segui \& Grainger, 1993).

Theoretical explanations of $\mathrm{N}$ effects generally invoke the notion that a written word can activate not only its own lexical entry but also the entries for other words of similar appearance. In certain conditions at least, activating those other lexical entries can facilitate the processing of the target word. Thus Andrews (1989) proposed an explanation for neighborhood size effects in terms of McClelland and Rumelhart's (1981) interactive activation model of visual word recognition, suggesting that the processing units responsible for identifying letters in words receive more top-down support from lexical units in the case of words with many neighbors than in the case of words with few neighbors.

Longer words tend to have fewer orthographic neighbors (Weekes, 1997). It is therefore possible that the previously reported word length and visual field interactions may in part reflect neighborhood size and hemispheric interactions. $\mathrm{N}$ values were obtained for the items used in six published experiments on length $\times$ VHF interactions from the MRC Psycholinguistic Database (Quinlan, 1993). Table 1 shows that word length was confounded with number of orthographic neighbors in all these previous studies. If it were shown that $\mathrm{N}$ affected word recognition in the LVF/RH (with smaller $\mathrm{N}$ values being associated with worse performance) but not in the RVF/ $\mathrm{LH}$, than this confound would have to be taken seriously.

Only one previous lateralization study has manipulated orthographic neighborhood size in the two hemispheres. Fiset and Arguin (1999) presented five-letter words varying in their number of orthographic neighbors in a lateralized lexical decision task to normal readers. Reaction times were not significantly different for large and small $\mathrm{N}$ words, but error rates were greater for larger $\mathrm{N}$. They did not find any interaction between $\mathrm{N}$ and visual field. Although Fiset and Arguin (1999) did not report N values for the large $\mathrm{N}$ group of words, it may be that these values were not as large as the $\mathrm{N}$ values typically associated with four letter words (that were used in the lateralization studies presented in Table 1). Thus to test whether $\mathrm{N}$ affects LVF but not RVF performance it is better to use four-letter words that have a broader range of $\mathrm{N}$ values than five-letter words.

Experiment 1 was designed to investigate the possible interaction between $\mathrm{N}$ and VHF performance in a lateralized lexical decision task on high and low $\mathrm{N}$ words of one length (four letters). Experiment 1 also included a central presentation condition. 


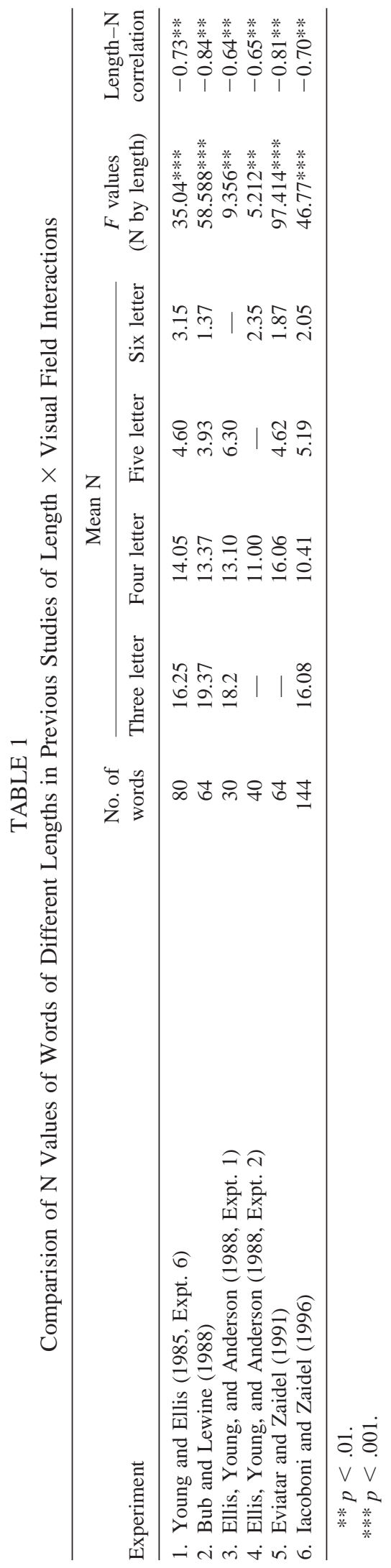




\section{EXPERIMENT 1}

\section{Method}

\section{Subjects}

Twenty-four native English speakers served as subjects. All of the subjects had normal or correctedto-normal vision and were ages 18-29 (mean age 19.7, SD 1.9). Each subject received either a course credit or $£ 2$ for his/her participation. All the subjects were right-handed and scored at least 80 on the Edinburgh test (Oldfield, 1971). Nine were males, 15 females.

\section{Design and Materials}

Stimuli. One hundred twenty four-letter English content words (nouns, verbs, and adjectives) and 120 four-letter nonwords were used as stimuli. Half of the words had fewer than 10 orthographic neighbors (mean number of neighbors 6.2). These words formed the low-N group. The remaining words all had more than 12 neighbors (mean 17.0). These formed the high- $\mathrm{N}$ group. The low and high-N sets were matched on written frequency (Kučera \& Francis, 1967), imageability and age of acquisition. The words were divided to six sets, created from the combinations of three different presentation locations (RVF, LVF and center) and two neighborhood sizes, with 20 words in each set. The six sets were also matched for written word frequency, imageability, and age of acquisition (see Table 2). The stimuli for Experiment 1 are presented in Appendix 1.

The stimuli (words and nonwords) were presented in 28-point lowercase Helvetica font. The letters appeared white on a blue background to minimize flicker. The stimuli were presented for $150 \mathrm{~ms}$ at a displacement of $2.5^{\circ}$ from the fixation point to the center of the word or nonword. The displacement was to the left or to the right of a central focus point (LVF and RVF, respectively) or in the center of the screen.

Design. Each subject was assigned to one of the six versions of the experiment. The different versions rotated the six word sets across the experimental conditions. Each session began with 10 practice trials to introduce the task, followed by 24 additional practice trials of centrally presented letter strings, where the task was to perform lexical decision. Thirty-six additional practice trials presented words and nonwords at different length at the center or to the left or to the right of the fixation point. Every target stimuli was presented just once to each subject such that we had 240 trials (words and nonwords) per subject. The within subject factors for words were $\mathrm{N}$ group (high vs low) and presentation location (RVF, LVF, or screen center), each within subject combination was repeated 20 times.

\section{Procedure}

Stimulus presentation was controlled by an IBM Pentium computer, 586 processor, on 17" SVGA display. The subjects sat at a viewing distance of $50 \mathrm{~cm}$, with the head positioned in a chin-rest. The experiment was designed using Super-Lab version 2.

Each trial began with an " $\mathrm{X}$ " appearing in the center of the screen for $400 \mathrm{~ms}$. For the first trial, the $\mathrm{X}$ remained for $2000 \mathrm{~ms}$ and disappeared when the target word was presented. The $\mathrm{X}$ would again reappear to allow projection of the next target word. Targets were briefly presented for $150 \mathrm{~ms}$ (either a word or a nonword), to the left or to the right of the focus point. The subject's task was to decide, as quickly and as accurately as possible, whether the stimulus was a legal English word or a nonword. Subjects responded by pressing one of two available response keys, labeled "word" and "nonword" on a standard QWERTY keyboard. For half of the subjects the response "word" was made by pressing the " $\mathrm{N}$ " key, and "nonword" by pressing the " $\mathrm{V}$ " key. For half of the subjects the response keys were reversed. The subjects were randomly assigned to one of the two response options.

\section{Results}

Two repeated-measures analysis of variance were performed, one with RT for correct responses to words as the dependent variable and one with percentage of correct responses for word stimuli as the dependent variable. The within-subject factors for the words stimuli were neighborhood size (low and high) and location (RVF, central, or LVF presentation). The results are shown in Table 3. 


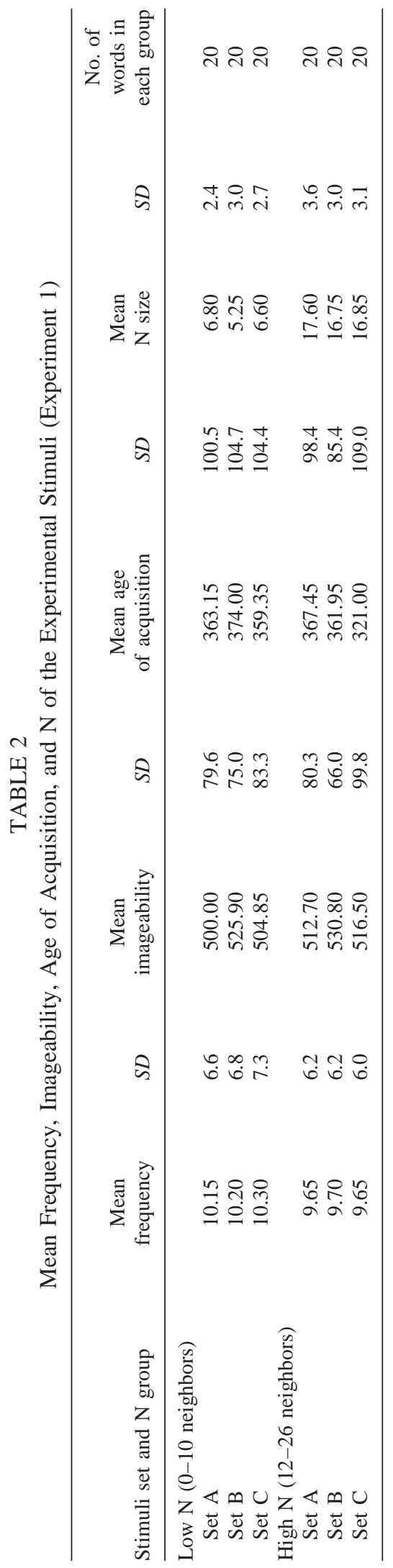


TABLE 3

Mean Reaction Times (Standard Deviations) in Milliseconds and Accuracy Scores to Words as a Function of Presentation Location and Neighborhood Size (Experiment 1)

\begin{tabular}{lccc}
\hline & \multicolumn{3}{c}{ Position } \\
\cline { 2 - 4 } & LVF & Center & RVF \\
\hline Low N & & & \\
Mean RT & 577 & 490 & 514 \\
$(S D)$ & $(88)$ & $(72)$ & $(78)$ \\
$\%$ correct & 83 & 93 & 90 \\
High N & & & \\
Mean RT & 542 & 457 & 515 \\
$(S D)$ & $(71)$ & $(74)$ & $(77)$ \\
$\%$ correct & 88 & 96 & 91 \\
\hline
\end{tabular}

\section{Reaction Time}

Only correct RTs were analyzed. A main effect of location $[F(2,22)=53.6, p$ $<.001]$ was found. Performance to central words (mean $=473 \mathrm{~ms}$ ) was significantly faster than to RVF stimuli (mean $=515 \mathrm{~ms}$ ), which was in turn faster than to LVF stimuli (mean $=560 \mathrm{~ms}$ ) (the significant differences were indicated using Scheffe post hoc analysis, $p<.05)$.

Orthographic neighborhood size (N) significantly affected lexical decision latency $[F(1,23)=18.83, p<.001]$. The RT for low-N words was significantly longer $($ mean $=527 \mathrm{~ms})$ compared to high-N words $($ mean $=505 \mathrm{~ms})$.

Location and neighborhood size interacted significantly $[F(2,22)=3.57, p<$ .05]. The interaction is shown in Fig. 1. RVF performance was similar for high-N words $($ mean $=514)$ and low-N words $($ mean $=515)$, as opposed to LVF and central presentation, where performance improved significantly for higher $\mathrm{N}$ values, as indicated using Scheffe post hoc analysis, $p<.05$.

\section{Accuracy}

A main effect of location $[F(2,22)=20.3, p<.001]$ was found. Performance to central words (mean $=94.9 \%$ correct) was significantly better than to RVF stimuli $($ mean $=90.1 \%)$, which was in turn better than LVF stimuli (mean $=86.3 \%$ ) (the significant differences were indicated using Scheffe post hoc analysis, $p<.05$ ). Orthographic neighborhood size $(\mathrm{N})$ significantly affected lexical decision accuracy $[F(1,23)=15.11, p<.001]$. Accuracy for high-N words was significantly better

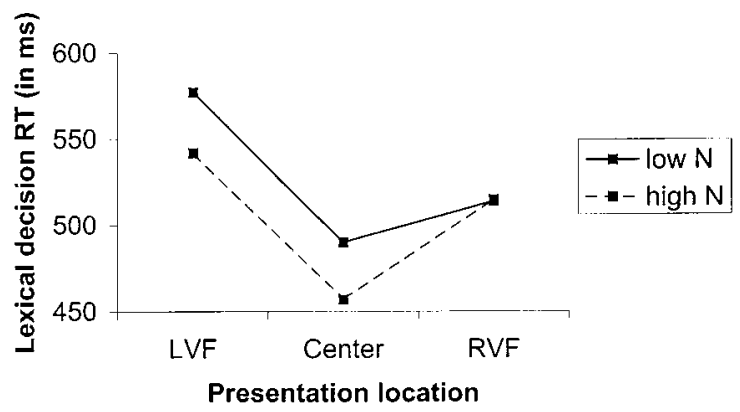

FIG. 1. Reaction times as a function of presentation location (central or parafoveal) and orthographic neighborhood size (N) (Experiment 1). 
$($ mean $=92.0 \%)$ than for low-N words $($ mean $=88.5 \%)$. The visual field by $\mathrm{N}$ interaction was not significant.

\section{Reaction Time and Accuracy for Nonwords}

Neighborhood size did not apply for nonwords. A main effect of location $[F(2$, $22)=21.2, p<.001]$ was found. The RTs to central nonwords (mean $=535 \mathrm{~ms}$ ) were significantly faster than to RVF stimuli (mean $=584 \mathrm{~ms}$ ) and LVF stimuli (mean $=594 \mathrm{~ms}$ ), which did not differ (the significant differences were indicated using Scheffe post hoc analysis, $p<.05$ ). The same pattern was found for accuracy $[F(2,22)=15.7, p<.01]$, where performance to central nonwords (mean $=89 \%$ ) was significantly better than to RVF $(84 \%)$ or LVF $(83 \%)$.

\section{Discussion}

We used a broad range of $\mathrm{N}$ values in the first experiment in order to find out the "natural' effects of orthographic neighborhood size when words are presented to the fixation point and in lateralized presentation. We replicated the previously reported $\mathrm{N}$ facilitation effects for lexical decision when words are presented in central presentation (e.g., Perea, 1998). There are almost no previous studies to compare our results to, but we have found the same facilitation effect of "typical" words (with high N) when words were presented to LVF, but orthographic neighborhood size did not affect performance when words were presented to the RVF and hence to the LH. The only study we are aware of that manipulated $\mathrm{N}$ in a lateralized paradigm did not find any interaction of $\mathrm{N}$ and visual field (Fiset \& Arguin, 1999).

The direction of this interaction seems reasonable when reassessing the previously length and visual field reported interactions (see Table 1 for references). The LVF performance is inhibited under conditions of low N (unique words); hence, its performance for the longer words, which have typically low $\mathrm{N}$ values, is slower than to the shorter words, which have many orthographic neighbors. Thus, the difference in performance between the visual fields was the greatest for the six-letter words because it reflected not only the length effects, but also the slower LVF performance to low-N words (as are most of the six-letter words in natural language). The smaller gap in performance for four-letter words reflected the better LVF performance for common words (better relatively to LVF performance to longer, unique words). In the general discussion we discuss further the asymmetrical $\mathrm{N}$ effects in the hemispheres.

We have shown by now that $\mathrm{N}$ affected LVF but not RVF. We now need to see if length continues to affect LVF but not RVF performance once $\mathrm{N}$ is controlled. Experiment 2 therefore compared lexical decision performance to five- and eightletter words, that have the same $\mathrm{N}$ values, in central and lateralized presentation (as in Experiment 1). The words differed in number of letters, but not in the physical length. This was done in order to equate visual acuity in the parafoveal conditions. Bruyer and Janlin (1989) inserted extra spacing into four-letter words, making them the same physical length as seven-letter words, but continued to observe the VHF $\times$ length interaction, suggesting that number of letters rather than physical length is the critical factor (or perhaps that the interaction of VHF is with some other factor that correlates with number of letters, such as $\mathrm{N}$ ).

\section{EXPERIMENT 2}

\section{Method}

\section{Subjects}

Twenty-four native English speakers served as subjects. All of the subjects had normal or correctedto-normal vision and were ages 18-25 (mean age 18.9, SD 1.3). Each subject received either a course 
credit or $£ 2$ for his/her participation. All the subjects were right-handed and scored at least 80 on the Edinburgh test (Oldfield, 1971). Twelve were males, 12 females.

\section{Design and Materials}

Stimuli. Ninety-six English content words and 96 nonwords were used as stimuli. Half of the words had five letters and half had eight letters. Word sets were matched for written frequency, imageability, age of acquisition, and N. The words were divided to six sets, created from the combinations of three different presentation locations (RVF, LVF, and center) and two lengths, 16 words in each set. The six sets were also matched for written word frequency, imageability, age of acquisition, and $\mathrm{N}$ (see Table 4). The stimuli for Experiment 2 are presented in Appendix 2.

The nonwords were generated from another word pool by changing one letter, such that the nonwords were legal and pronounceable. Nonwords were also made of five and eight letters in equal proportion.

The stimuli were presented as in Experiment 1. The five-letter words were spaced such as their physical length was equal to the eight-letter words. A pilot study with 10 subjects found that responses to normal and spaced five-letter words did not differ significantly and did not interact with visual field. These findings are in line with Bruyer and Janlin (1989). Figure 2 illustrates the appearance of the spaced fiveletter and the eight-letter stimuli.

Design. Each subject was assigned to one of the six versions of the experiment. The different versions rotated the six word sets along the experimental conditions. Practice trials were as in Experiment 1. Every target stimuli was presented once such that we had 192 trials (words and nonwords) per subject. The within subject factors (for words) were word length (five and eight letters) and presentation location (RVF, LVF, or screen center). Each within subject combination was repeated 16 times.

Procedure. The procedure was as in Experiment 1.

\section{Results}

Two repeated-measures analysis of variance were performed, one with RT for correct responses to words as the dependent variable and one with percentage of correct responses for word stimuli as the dependent variable. The within-subject factors for the words stimuli were word length and presentation location (RVF/LVF or central presentation). The results are shown in Table 5.

\section{Reaction Time}

Only correct RTs were analyzed. A main effect for presentation location $[F(2,22)$ $=7.76, p<.01]$ was found. Overall, performance to central words (mean $=453$ $\mathrm{ms}$ ) and RVF words (mean $=467 \mathrm{~ms}$ ) was significantly faster than to LVF stimuli $($ mean $=500 \mathrm{~ms})$ (the significant differences were indicated using Scheffe post hoc analysis, $p<.05)$. Word length significantly affected lexical decision latency $[F(1$, $23)=5.40, p<.05]$. Overall, RT for eight-letter words was significantly longer $($ mean $=482 \mathrm{~ms})$ compared to five-letter words (mean $=463 \mathrm{~ms})$.

Presentation location and word length interacted significantly $[F(2,22)=5.03, p$ $<$.05]. Word length affected performance only for LVF words, with significantly longer latencies to eight-letter words (mean $=520 \mathrm{~ms}$ ) than to five-letter words (mean $=480 \mathrm{~ms})$. The interaction is presented in Fig. 3 .

\section{Accuracy}

Accuracy scores for words were not significantly affected by visual field or word length. 


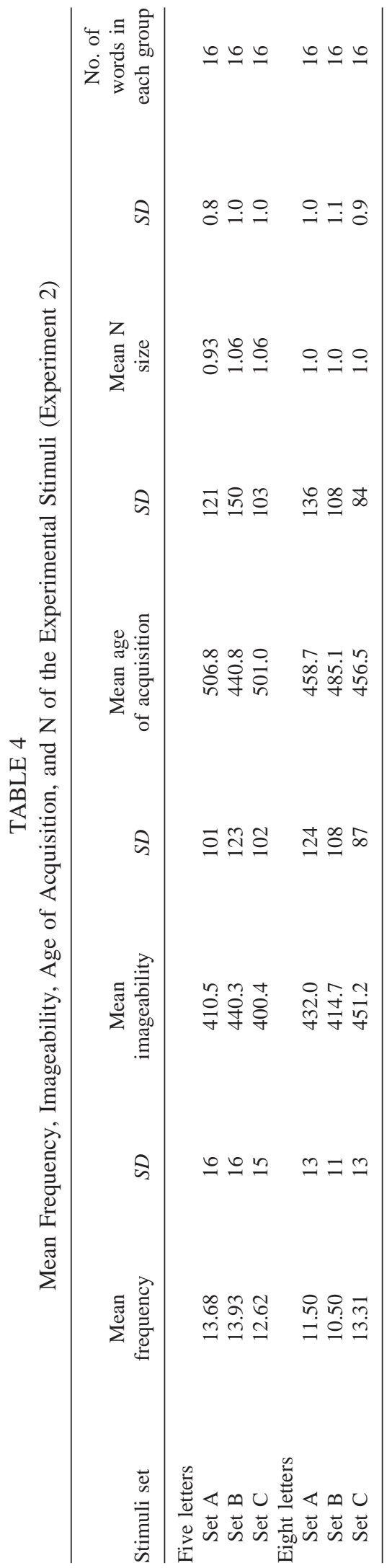




\section{A L G A E ALTITUDE}

FIG. 2. Demonstration of the spaced five-letter stimuli and eight-letter stimuli (Experiment 2).

\section{Reaction Time and Accuracy for Nonwords}

A main effect for nonword length $[F(2,22)=5.38, p<.05]$ was found for RT. Performance to five-letter nonwords (mean $=546 \mathrm{~ms}$ ) was significantly faster than to eight-letter nonwords (mean $=567 \mathrm{~ms}$ ). No other effects were found.

\section{Discussion}

Experiment 2 found the previously reported length and visual field interaction when the five- and eight-letter words were matched for $\mathrm{N}$ values and had the same physical length. The matched $\mathrm{N}$ values imply that many of the words in this experiment were unique in the sense they had few neighbors $($ mean $=1$ ). Word length affected latencies only for LVF words, but not for centrally presented or RVF words. The similarity in performance in the fovea and in RVF presentations may reflect similar word recognition processes, which involve a greater degree of parallel processing than for words presented in the LVF where RT was a function of number of letters.

The natural question now is: What is the joint effect of $\mathrm{N}$ and length on word recognition in the RVF and LVF? Experiment 3 set out to discover whether the previously reported interaction between word length and VF would hold for words of both high and low $\mathrm{N}$ and conversely whether the interaction between $\mathrm{N}$ and VF would hold for words of different lengths.

\section{EXPERIMENT 3}

\section{Method}

\section{Subjects}

Twenty-four English speakers served as subjects. All of the subjects had normal or corrected-to-normal vision and were between the ages of 18 and 26 (mean age 19.1 SD 1.2). Each subject received either

TABLE 5

Mean Reaction Times (Standard Deviations) in Milliseconds and Accuracy Scores to Words as a Function of Presentation Location and Word Length (Experiment 2)

\begin{tabular}{lccc}
\hline & \multicolumn{3}{c}{ Position } \\
\cline { 2 - 4 } & LVF & Center & RVF \\
\hline Five letter & & & \\
Mean RT & 480 & 449 & 462 \\
$(S D)$ & $(90)$ & $(75)$ & $(93)$ \\
$\quad \%$ correct & 86 & 89 & 88 \\
Eight letter & & & \\
Mean RT & 520 & 456 & 471 \\
$(S D)$ & $(97)$ & $(80)$ & $87)$ \\
$\%$ correct & 83 & 90 & 88 \\
\hline
\end{tabular}




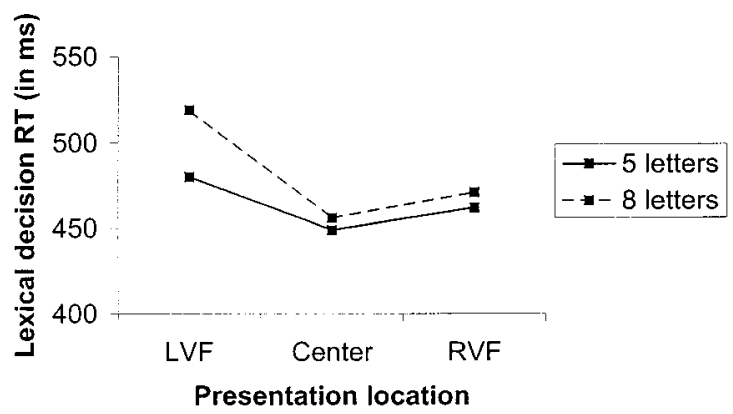

FIG. 3. Reaction times as a function of presentation location (central or parafoveal) and word length (Experiment 2).

a course credit or $£ 2$ for his/her participation. All the subjects were right-handed and scored at least 80 on the Edinburgh test (Oldfield, 1971). Ten were males, 14 females.

\section{Design and Materials}

Stimuli. Ninety-six English content words and 96 nonwords were used as stimuli. Thirty-two words had four letters, 32 had five letters, and 32 had six letters. Half of the words of each length had fewer than five orthographic neighbors (mean number of neighbors 2.4). These words formed the low-N group. The remaining words all had more than six neighbors (mean 7.7). These formed the high- $\mathrm{N}$ group. The six word lists, created from the combinations of three different lengths and two neighborhood sizes, were matched for written word frequency and imageability (see Table 6). The stimuli for Experiment 3 are presented in Appendix 3.

Ninety-six nonwords were generated from another word pool by changing one letter such that the nonwords were legal and pronounceable. Nonwords were also made of four, five, and six letters in equal proportion. The stimuli (words and nonwords) were presented as in Experiment 1.

Design. The practice trials were as in Experiment 1. Every target stimulus was presented twice, once in each visual field. Half of the targets were presented first to the left visual field, half to the right. There were 384 experimental trials for each subject. The stimuli were presented in a random order with the restriction that no more than three successive words or nonwords or three successive LVF or RVF trials occurred together.

Procedure. The procedure was as in Experiment 1.

\section{Results}

Two repeated-measures analysis of variance were performed, one with RTs for correct responses to words as the dependent variable and one with percentage of correct responses for word stimuli as the dependent variable. The within-subjects factors for words were word length (four-, five-, or six-letter strings), neighborhood size (low and high), and visual field (RVF/LVF). The results are shown in Table 7.

\section{Reaction Time}

A main effect for visual field $[F(1,23)=20.7, p<.01]$ was found. Overall, RTs to RVF words (mean $=484 \mathrm{~ms}$ ) were significantly faster than to LVF words (mean $=530 \mathrm{~ms})$. Word length significantly affected lexical decision latency $[F(2,46)=$ $14.89, p<.01]$. Overall, RTs for six-letter words were significantly longer (mean $=523 \mathrm{~ms}$ ) than RTs to four- or five-letter words (502 ms for four-letter words and $501 \mathrm{~ms}$ for five-letter words), as indicated by Scheffe post hoc analysis.

Visual field and neighborhood size interacted significantly $[F(1,23)=8.65, p<$ .01]. The RTs were significantly faster to high-N than low-N words in the LVF but there was no significant effect of $\mathrm{N}$ in the RVF. The triple interaction of visual field, 


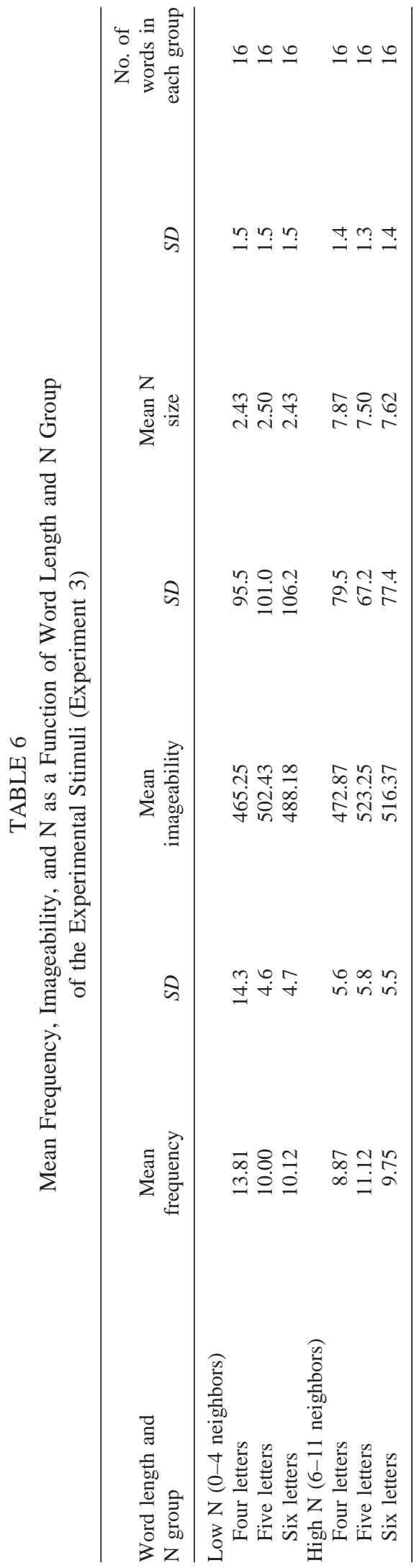




\section{TABLE 7}

Mean Reaction Times (Standard Deviations) in Milliseconds and Accuracy Scores to Words as a Function of Visual Field, Neighborhood Size, and Word Length (Experiment 3)

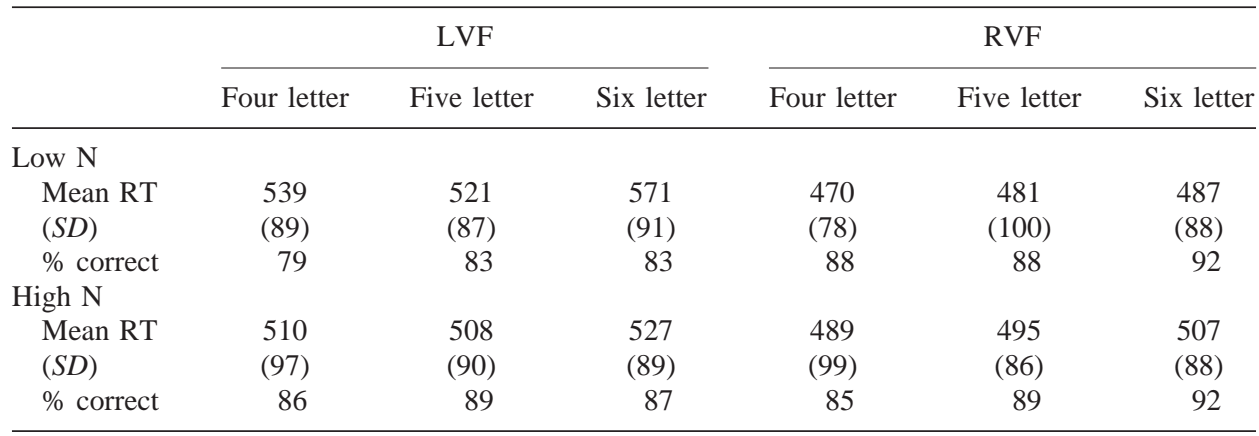

neighborhood size, and word length was also significant $[F(2,22)=4.795, p<.05]$ (see Fig. 4). Length effects in the LVF were strongest for small N words. Several separate repeated-measures analyses were further performed to investigate this interaction. Length and visual field interacted significantly for low-N words $[F(2,22)=$ $3.864, p<.05]$, but not for high-N words $[F(2,22)<1, n s]$. For LVF stimuli, $\mathrm{N}$ interacted significantly with length $[F(2,22)=3.458, p<.05]$ such that responses to longer words were significantly slower for low $\mathrm{N}$, but did not differ significantly for high $\mathrm{N}$. The interaction between $\mathrm{N}$ and length was far from significant for RVF stimuli $[F(2,22)<1, n s]$.

Simple main effects tests showed a significant length effect only for low-N words that were presented to the LVF, but not for high-N words and not for low-N words in the RVF. The RTs to the six-letter words were significantly slower than to fourand five-letter words only for low-N LVF words.

\section{Accuracy Scores}

A main effect for visual field $[F(1,23)=8.64, p<.01]$ was found. Performance to RVF words (mean $=88.9 \%$ ) was significantly more accurate than to LVF stimuli $($ mean $=84.9 \%)$.

Visual field and neighborhood size interacted significantly $[F(1,23)=10.51, p$ $<.01]$. RVF performance did not differ significantly for high-N (mean $=88.4 \%$ )

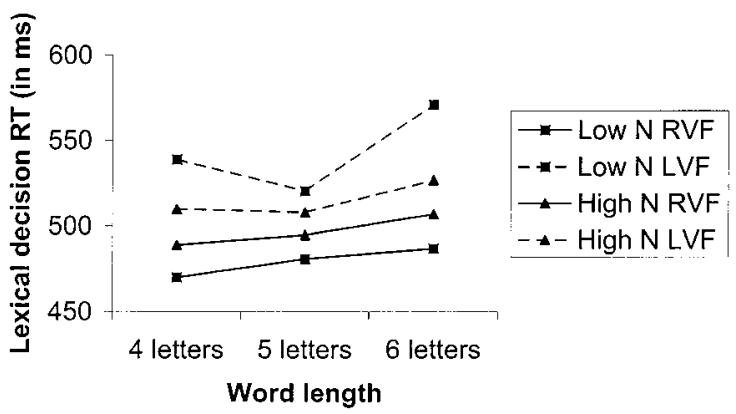

FIG. 4. Reaction times as a function of visual field and word length for words with many and few orthographic neighbors (Experiment 3). 
and low-N (mean $=89.1 \%$ ) words, in contrast, LVF performance improved significantly for higher $\mathrm{N}$ values $(81.6 \%$ for low $\mathrm{N}$ and $87.7 \%$ to high $\mathrm{N}$ ).

\section{Reaction Time and Accuracy for Nonwords}

The within-subjects variables for nonwords were length and visual field. Only length significantly affected lexical decision latency for nonword RTs $[F(2,46)=$ $16.5, p<.01]$. The RTs for six-letters nonwords were significantly longer (mean = $648 \mathrm{~ms}$ ) compared to five-letter nonwords (mean $=620 \mathrm{~ms}$ ), which were significantly longer than four-letter nonwords $($ mean $=591 \mathrm{~ms}$ ), as indicated by Scheffe post hoc analysis. No other effects were found.

\section{Discussion}

We have shown above that word length was confounded with orthographic neighborhood size in previous studies of length $\times$ VHF interactions (see Table 1). Experiment 1 showed that $\mathrm{N}$ interacted with $\mathrm{VHF}$ when length is controlled, while Experiment 2 showed that length interacted with VHF when $\mathrm{N}$ is controlled. Experiment 3 indicates that when length and $\mathrm{N}$ are both varied, word length only affects performance on low $\mathrm{N}$ words in the LVF. As in Experiment 1, we found again that RTs were faster to high- than low-N words in the LVF but not in the RVF.

\section{GENERAL DISCUSSION}

Previous lateralization studies that reported word length and visual field interaction have failed to control orthographic neighborhood $(\mathrm{N})$ values of the target words. As we have shown in Table 1, the uncontrolled $\mathrm{N}$ caused a systematic effect such that the longer words that were used had significantly fewer neighbors than the shorter words. Thus the length effects reported in these studies (Bub \& Lewine, 1988; Ellis et al., 1988; Eviatar \& Zaidel, 1991; Yacoboni \& Zaidel, 1996; Young \& Ellis, 1985) were confounded with $\mathrm{N}$ effects.

Experiment 1, which used a broad range of $\mathrm{N}$ values for four-letter words, showed that LVF performance improved for common words (with high $\mathrm{N}$ ) compared to low$\mathrm{N}$ words; but $\mathrm{N}$ did not facilitate performance in the RVF (LH). The experiment successfully repeated the well-established facilitatory $\mathrm{N}$ effects for lexical decision for centrally presented words (Laxon et al., 1988, 1994). Experiment 2 investigated whether VHF and length would interact once $\mathrm{N}$ was controlled. They did. The aim of Experiment 3 was to test the previously reported length and visual field interaction while at the same time varying $\mathrm{N}$. The results suggested that the $\mathrm{VHF} \times$ length interaction is true only under conditions of low $\mathrm{N}$. When $\mathrm{N}$ was large, neither hemifield was affected by length, as opposed to low-N conditions, where LVF performance decreased for longer words.

Why is the right hemisphere more sensitive to $\mathrm{N}$ size than the left hemisphere? Is the process of orthographic activation suggested by Andrews (1989) specific to, or more efficient in, the right hemisphere? We can find some indirect evidence that suggests that this is the case. Rugg and Barrett (1987) recorded event-related potentials (ERPs) in three experiments involving a rhyme-judgment task. They found a right-hemisphere-based effect with orthographically similar items that resulted from the operation of an orthographic priming mechanism. Crossman and Polich (1988) found type of task (phonological and orthographic) and VF interaction such that phonological priming affected more the RVF, but orthographic priming was more effective in LVF. 
The most convincing evidence for the claim that the $\mathrm{RH}$ is more sensitive to orthography comes from a study by Chiarello (1985), where semantic similarity (e.g., inchyard) produced larger priming for right visual field (RVF/LH) stimuli, but orthographic priming (e.g., beak-ear) was larger in the left visual field (LVF/RH). Phonological priming was obtained only in the RVF. These results suggest that the hemispheres may utilize different information to achieve lexical access. Chiarello's study (1985) did not test directly orthographic neighborhood effects in the hemispheres, but may lead indirectly to the conclusion that during the process of word recognition, the $\mathrm{RH}$ tends to be more responsive to the orthographical properties of the target word and hence is more affected by $\mathrm{N}$ size than the LH.

Recently Chiarello (in press) has suggested a new distinction between the hemispheres. She argued that words received by the LH very rapidly achieve deeper or more abstract encoding, while words received by the RH maintain and perhaps even amplify early encoding even when deeper level codes become available. Using her interpretation, it may be that the delayed letter-encoding stage in the RH enables the activation of words that share the same letters with the target word (hence, orthographic neighbors). This pattern of activation is not found in the LH, since words are promoted rapidly to deeper (and more efficient) encoding stages. Thus neither word length nor orthographic neighborhood size (both characteristic of letter-level encoding) affect LH word recognition. In addition to the current findings, this new theory is supported by previous studies that have found faster activation in the LH than in the RH for normal words (Collins, 1999; Koivisto, 1997, 1998). But these findings are indirect, thus further experiments are required to test this potentially interesting theory.

In summary, we have shown that number of orthographic neighbors (N) affects lexical decision RT to words in the LVF but not in the RVF (Experiments 1 and 2). This result suggests more widespread orthographic activation in the right hemisphere than in the left. We have also shown that word length has been confounded with $\mathrm{N}$ in previous studies that have reported an interaction between VHF and word length such that length has more effects in the LVF/right hemisphere than in the RVF/left hemisphere. The nature of the $\mathrm{N} \times \mathrm{VHF}$ interaction in Experiment 1 raised the possibility that the previously reported interaction of length with VHF could be entirely due to a confound with N. Experiment 2 showed that this was not the case: word length interacted with VHF even when $\mathrm{N}$ was controlled. The stimuli used in Experiment 2 tend all to be of low $\mathrm{N}$, and when length and $\mathrm{N}$ were varied together in Experiment 3 the length $\times$ VHF interaction was found to hold only for low-N words.

Effects of $\mathrm{N}$ presumably reflect interactions between letter and word levels of representation. Such interactions appear to characterize the right hemisphere more than the left, possibly because processing in the left hemisphere proceeds rapidly beyond orthographic levels to semantic and phonological representations. Having many neighbors seems to help longer words presented to the right hemisphere to overcome the effects of a slower mode of processing within that hemisphere. 
APPENDIX 1

Stimuli for Experiment 1

\begin{tabular}{|c|c|c|c|c|c|}
\hline \multicolumn{3}{|c|}{ Low $\mathrm{N}$} & \multicolumn{3}{|c|}{ High $N$} \\
\hline Set A & Set B & Set C & Set A & Set B & Set C \\
\hline acre & ally & babe & bush & beam & bite \\
\hline beau & arch & coal & cage & bolt & boot \\
\hline cube & aunt & crab & cone & cock & cake \\
\hline earl & chop & fury & dell & deer & cart \\
\hline envy & diet & gasp & dent & duck & dock \\
\hline germ & disc & grip & dusk & dump & doll \\
\hline gulf & duel & jerk & hank & gang & hail \\
\hline heap & echo & lens & herd & gore & hint \\
\hline howl & fork & liar & hide & hive & hush \\
\hline lion & lamb & oven & hind & hose & joke \\
\hline newt & menu & pity & hump & lime & keel \\
\hline oath & omen & raid & mall & maze & leak \\
\hline palm & plug & riot & mast & peck & mist \\
\hline shed & prey & saga & mule & pump & pest \\
\hline soap & roar & sand & nail & rent & port \\
\hline swim & suds & sigh & rust & rope & rake \\
\hline thaw & tomb & stew & seal & tuck & reed \\
\hline veil & trim & veto & tack & vale & sock \\
\hline verb & watt & weep & tear & vine & tent \\
\hline wool & yelp & worm & tide & zone & yore \\
\hline
\end{tabular}

APPENDIX 2

Stimuli for Experiment 2

\begin{tabular}{|c|c|c|c|c|c|}
\hline \multicolumn{3}{|c|}{ Five letter } & \multicolumn{3}{|c|}{ Eight letter } \\
\hline Set A & Set B & Set $\mathrm{C}$ & Set A & Set B & Set $C$ \\
\hline ALGAE & DEBUT & ABYSS & APERTURE & ASSEMBLE & ALTITUDE \\
\hline AMITY & DEITY & ALIAS & ARTIFICE & BLESSING & ASBESTOS \\
\hline ANNEX & LOGIC & EXTRA & COMPOSER & CRUCIFIX & CARRIAGE \\
\hline AUDIT & LYMPH & FRAUD & DISGRACE & EDUCATOR & COOLNESS \\
\hline CHAIN & MAGIC & HABIT & DWELLING & ESTIMATE & DISTRESS \\
\hline DIRGE & PAUSE & IRONY & FOOTSTEP & FOOTBALL & DIVIDEND \\
\hline ERROR & PIANO & MANOR & FULLNESS & IMMUNITY & DULLNESS \\
\hline ETHER & SYNOD & ODOUR & GOODNESS & INACTION & EMULSION \\
\hline OFFAL & THIEF & PLAZA & HENCHMAN & INSTINCT & FAREWELL \\
\hline QUAIL & TWEED & PROOF & IMPUNITY & LEGALITY & KINDNESS \\
\hline REALM & UNCLE & REIGN & KNITTING & LITERATE & LAUGHTER \\
\hline ROUTE & UPSET & SUITE & MISTRESS & MOLASSES & OPTIMISM \\
\hline SHRUG & VENOM & TROOP & RELEGATE & MONUMENT & OUTHOUSE \\
\hline SPLIT & WALTZ & ULCER & SICKNESS & PALTERER & SHORTAGE \\
\hline THEFT & WHOOP & VIGIL & SUNSHINE & PRETENCE & TENDENCY \\
\hline WAIST & YACHT & YUCCA & TRANSFER & SYLLABLE & VACATION \\
\hline
\end{tabular}


APPENDIX 3

Stimuli for Experiment 3

\begin{tabular}{|c|c|c|c|c|c|}
\hline \multicolumn{3}{|c|}{ Low $\mathrm{N}$} & \multicolumn{3}{|c|}{ High $N$} \\
\hline Four letter & Five letter & Six letter & Four letter & Five letter & Six letter \\
\hline ALLY & ALGAE & AERIAL & ACRE & BLADE & BANKER \\
\hline $\mathrm{ARCH}$ & BLOOM & BURIAL & ARID & BROOK & BREEZE \\
\hline DISC & CLIFF & CHERRY & BOOT & BUNCH & BUBBLE \\
\hline DUEL & IRONY & FRENZY & CHOW & CURSE & BUFFER \\
\hline DUMB & OLIVE & GOSPEL & EARL & DAIRY & COPPER \\
\hline DUTY & REIGN & KITTEN & FORK & FLAME & DENIAL \\
\hline ECHO & SAUCE & MORTAL & FURY & FLOCK & FIDDLE \\
\hline ENVY & SKIRT & OUTSET & GERM & GABLE & GINGER \\
\hline EXIT & STOOL & PARDON & LENS & GLOVE & HAMMER \\
\hline MYTH & SWORD & PLANET & PITY & MOUSE & KETTLE \\
\hline RIOT & THEFT & RABBIT & SIGH & PASTE & MARVEL \\
\hline SAGA & TOKEN & REPAIR & SLIT & SHAME & PARISH \\
\hline SUDS & TOPIC & SORROW & SWIM & SLICE & SINGER \\
\hline TOMB & TRUNK & UNREST & THAW & SPIKE & STRIDE \\
\hline VETO & WHEAT & VIOLET & WATT & STAIN & TICKET \\
\hline ZONE & YACHT & WILLOW & YELP & TRICK & TUMBLE \\
\hline
\end{tabular}

\section{REFERENCES}

Andrews, S. (1989). Frequency and neighbourhood effects on lexical access: Activation or search? Journal of Experimental Psychology: Learning, Memory, and Cognition, 15, 802-814.

Babkoff, H., Faust, M., \& Lavidor, M. (1997). Lexical decision, visual hemifield and angle of orientation. Neuropsychologia, 35, 487-495.

Bouma, H. (1973). Visual interference in the parafoveal recognition of initial and final letters of words. Vision Research, 13, 767-782.

Bruyer, R., \& Janlin, D. (1989). Lateral differences in lexical access: Word length vs. stimulus length. Brain and Language, 37, 258-265.

Bub, D. N., \& Lewine, J. (1988). Different modes of word recognition in the left and right visual fields. Brain and Language, 33, 161-188.

Chiarello, C. (1985). Hemisphere dynamics in lexical access: Automatic and controlled priming. Brain and Language, 26, 146-172

Chiarello, C. (1988). Lateralization of lexical processes in the normal brain: A review of visual halffield research. In H. A. Whitaker (Ed.), Contemporary reviews in neuropsychology. New York: Springer-Verlag.

Chiarello, C. (in press). Parallel systems for processing language: Hemispheric complementarity in the normal brain. In M. T. Banich \& M. Mack, (Eds.), Mind, brain and language: Multidisciplinary perspectives. Mahwah, NJ: Erlbaum.

Collins, M. (1999). Differences in semantic category priming in the left and right cerebral hemispheres under automatic and controlled processing conditions. Neuropsychologia, 37, 1071-1085.

Coltheart, M., Davelaar, E., Jonasson, J. T., \& Besner, D. (1977). Access to the internal lexicon. In S. Dornic (Ed.), Attention and performance VI: The psychology of reading. London: Academic Press.

Crossman, D. L., \& Polich, J. (1988). Hemispheric differences for orthographic and phonological processing. Brain and Cognition, 35, 301-312.

Ellis A. W., Young A. W., \& Anderson, C. (1988). Modes of word recognition in the left and right cerebral hemispheres. Brain and Language, 35, 254-273.

Eviatar, Z., \& Zaidel, E. (1991). The effects of word length and emotionality on hemispheric contribution to lexical decision. Neuropsychologia, 29, 415-428.

Fiset, S., \& Arguin, M. (1999). Case alternation and orthographic neighbourhood size effects in the left and right cerebral hemispheres. Brain and Cognition, 40, 116-118, doi: 10.1006/brcg.1999.1066.

Gill, K. M., \& McKeever, W. F. (1974). Word length and exposure time effects on the recognition of bilaterally presented words. Bulletin of the Psychonomic Society, 4, 173-175. 
Iacoboni, M., \& Zaidel E. (1996). Hemispheric independence in word recognition: Evidence from unilateral and bilateral presentations. Brain and Language, 53, 121-140.

Koivisto, M. (1997). The time course of semantic activation in the cerebral hemispheres. Neuropsychologia, 35, 497-504.

Koivisto, M. (1998). Categorial priming in the cerebral hemispheres: Automatic in the left hemisphere, postlexical in the right hemisphere? Neuropsychologia, 36, 661-668.

Kucera, H., \& Francis, W. N. (1967). Computational analysis of present day American English. Providence, RI: Brown Univ. Press.

Laxon, V. J., Coltheart, V., \& Keating, C. (1988). Children find friendly words friendly too: Words with many orthographic neighbours are easier to read and spell. British Journal of Educational Psychology, 58, 103-119.

Laxon, V., Masterson, J., \& Moran, R. (1994). Are children's representations of words distributed?: Effects of orthographic neighbourhood size, consistency and regularity of naming. Language and Cognitive Processes, 9, 1-27.

McClelland, J. L., \& Rumelhart, D. E. (1981). An interactive activation model of context effects in letter perception. I. An account of basic findings. Psychological Review, 88, 375-407.

Oldfield, D. P. (1971). The assessment and analyses of handedness: The Edinburgh inventory. Neuropsychologia, 9, 97-113.

Perea, M. (1998). Orthographic neighbours are not all equal: Evidence using an identification technique. Language and Cognitive Processes, 13, 77-90.

Perea, M., \& Pollatsek. A. (1998). The effects of neighbourhood frequency in reading and lexical decision. Journal of Experimental Psychology: Human Perception and Performance, 24, 767-779.

Quinlan, P. (1993). MRC Psycholinguistic Database for the Apple Macintosh (a software).

Rugg, M. D., \& Barrett, S. E. (1987). Event-related potentials and the interaction between orthographic and phonological information in a rhyme-judgment task. Brain and Language, 32, 336-361.

Segui, J., \& Grainger, J. (1990). Priming word recognition with orthographic neighbours: Effects of relative prime target frequency. Journal of Experimental Psychology: Human Perception and Performance, 16, 65-76.

Weekes, B. S. (1997). Differential effects of number of letters on word and nonword naming latency. Quarterly Journal of Experimental Psychology: Human Experimental Psychology, 50A, 439-456.

Young, A. W., Bion, P. J., \& Ellis, A. W. (1980). Studies toward a model of laterality effects for picture and word naming. Brain and Language, 11, 54-65.

Young, A. W., \& Ellis, A. W. (1985). Different methods of lexical access for words presented in the left and right visual hemifields. Brain and Language, 24, 326-358. 